\title{
In vitro development of pig preantral follicles cultured in a serum-free medium and the effect of angiotensin II
}

\author{
G. Shuttleworth ${ }^{1 *}$, F. Broughton Pipkin ${ }^{1}$ and M. G. Hunter ${ }^{2}$ \\ ${ }^{1}$ Division of Obstetrics and Gynaecology, School of Human Development, \\ The University of Nottingham, Queen's Medical Centre, Nottingham NG7 2UH, UK; and \\ ${ }^{2}$ Division of Animal Physiology, School of Biosciences, University of Nottingham, \\ Sutton Bonington LE12 5RD, UK
}

\begin{abstract}
A novel culture system is reported in which pig preantral follicles $(<300 \mu \mathrm{m}$ in diameter) with an intact thecal cell layer were isolated and cultured in a serum-free medium for up to 30 days. The medium supported follicle culture after isolation, while maintaining both somatic cell and oocyte viability. Follicles were cultured in groups ( $n=3$ per group) on collagen-coated wells for 16 days, during which they retained a three-dimensional structure, maintained oocyte viability and increased in diameter and number of somatic cells. Follicle culture for $\mathbf{3 0}$ days resulted in a further increase in number of cells, oocyte viability was maintained, and a significant increase in follicle diameter was observed $(P<0.001)$, with $29 \%$ of follicles forming an antrum. Follicles synthesized measurable quantities of progesterone
\end{abstract}

(168 pg per $100 \mu \mathrm{l}$ per $48 \mathrm{~h}$; no significant increase with time) and increasing quantities of oestradiol (136 pg per $100 \mu \mathrm{l}$ per $48 \mathrm{~h} ; \boldsymbol{P}<0.001$ with time). Further supplementation of the medium with $100 \mu \mathrm{mol}$ testosterone $\mathrm{I}^{-1}$ at day 28 resulted in a significant increase in oestradiol secretion by both antral $(P<0.01)$ and preantral follicles $(P<0.05)$. Culture over 30 days in medium with $\mathbf{1 0}^{-10}$ mol angiotensin II $^{-1}$ and further supplementation at day 28 with $100 \mu \mathrm{mol}$ testosterone $\mathrm{I}^{-1}$ also increased oestradiol synthesis $(P<0.001)$. These results show that viable preantral follicles may be cultured for extended periods, and indicate that the possible role of angiotensin II in folliculogenesis and steroidogenesis in early development of pig follicles requires further investigation.

\section{Introduction}

Current developments in IVF and animal cloning have resulted in an increasing demand for large quantities of oocytes and ovarian follicles at specific stages of development. The reliable culture of preantral follicles would go some way towards meeting this demand, while also potentially enabling the preservation and long-term storage of female germ cells. Various degrees of progress have been made in the culture of follicles from a number of species (for reviews, see Hartshorne, 1997; Telfer, 1998). Although there has been success in the culture of mouse preantral follicles with live pups being born (Spears et al., 1994), there has been less success in the culture of pig preantral follicles (Hirao et al., 1994; Flowers and Turner, 1996; Telfer, 1996). Hirao et al. (1994) reported the culture of pig preantral follicles with the result that some oocytes acquired meiotic competence and were penetrated by spermatozoa, although the resulting one-cell zygotes did not develop further. More recently, pig preantral follicles have been

*Address for correspondence: Reproductive Technologies, AgResearch, Ward Street, PO Box 40063, Upper Hutt, New Zealand

Email: gail.shuttleworth@agresearch.co.nz cultured to antral stages with the resulting oocytes being capable of fertilization and embryonic development $\mathrm{Wu}$ et al., 2001). However, in both of these studies, follicles were cultured in medium containing serum and, although the use of serum in culture medium is widespread, it invariably introduces unknown growth factors (with interbatch variability) and has also been shown to cause pig granulosa cells in vitro to undergo luteolysis (Picton et al., 1999).

The basis of any follicle culture technique requires the ability to isolate large numbers of healthy follicles from ovarian tissue. Murine follicles may be isolated by microdissection using fine needles (Qvist et al., 1990; Nayudu and Osborn, 1992). The technique is more difficult when applied to domestic species, which possess more collagenous stromal tissue within the ovary, although the technique has been applied to cows (Figueiredo et al., 1994; Hulshof et al., 1994; Saha et al., 2000), sheep (Cecconi et al., 1999; Amorim et al., 2000) and pigs (Wu et al., 2001). However, controlled exposure to collagenase has been successful for isolation of pig follicles (Greenwald, 1994; Hirao et al., 1994; Telfer, 1996). Pig preantral follicles have subsequently been cultured in Waymouth medium, although this was with the addition of serum (Donnelly and Telfer, 1994; Hirao et al., 1994). In the present study, the aim was to develop further a defined, 
serum-free medium. A similar medium has been developed for the culture of pig granulosa and theca cells that supported the maintenance of follicular phenotype in vitro and implicated the role of $\mathrm{FSH}$ and long R3 insulin-like growth factor I (IGF-I) (Picton et al., 1999; Shores et al., 2000).

Angiotensin II is the principal effector of the renin-angiotensin system. Although classically associated with the regulation of blood pressure and salt balance (Levy, 1998), the renin-angiotensin system has also been implicated in the mammalian ovary (August and Sealey, 1990). Components of the renin-angiotensin system including prorenin, renin and angiotensin II receptors have been demonstrated within pig ovaries (Hagemann et al., 1992; Nielsen et al., 1995; Shuttleworth et al., 2001). Given that it has been shown that $\mathrm{AT}_{1}$ receptors are localized to prepubertal granulosa cells (Shuttleworth et al., 2001), it would be pertinent to assess the effect of addition of angiotensin II to the culture medium.

Therefore, the aims of the present study were to establish a serum-free medium for the long-term culture of pig preantral follicles and to confirm the viability of follicles grown in this 'optimum' medium using a range of techniques. The role of angiotensin II in preantral folliculogenesis and steroidogenesis was also assessed.

\section{Materials and Methods}

\section{Materials}

All reagents were obtained from Sigma Chemical Co. (Poole). All unsupplemented tissue culture media were obtained from Invitrogen Corporation (Paisley) and all tissue culture disposable plastics were obtained from Nunc (Paisley) unless otherwise specified. All culture media compositions used were equilibrated to $37^{\circ} \mathrm{C}, 5 \% \mathrm{CO}_{2}$. Prepubertal (age 12-15 weeks) ovarian tissue (Large White hybrid pigs) was obtained from a local abattoir and transported to the laboratory within $1 \mathrm{~h}$ of collection in warm medium 199 (M199) containing 0.2 iu penicillin I $^{-1}$

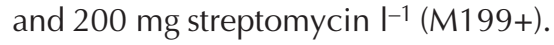

\section{Isolation of preantral follicles}

Ovaries were sliced into pieces (1-2 mm thickness) and incubated in $10 \mathrm{ml} \mathrm{M} 199+$ containing $0.2 \% \quad(\mathrm{w} / \mathrm{v})$ collagenase (type $1 \mathrm{~A})$ in a shaking waterbath $\left(39^{\circ} \mathrm{C}\right.$; Hirao et al., 1994) for a maximum of $30 \mathrm{~min}$, until test pieces of tissue could be teased apart easily using 25G needles. The tissue was washed in four changes of M199+ plus $0.4 \%$ $(\mathrm{w} / \mathrm{v})$ bovine serum albumin (BSA: fraction $\mathrm{V}$, cell culture tested). The preantral follicles were isolated and washed in three changes of Way+ (Waymouth medium: $2 \mathrm{mg}$ sodium pyruvate $\mathrm{I}^{-1}, 200$ iu penicillin $\mathrm{ml}^{-1}, 200 \mu \mathrm{g}$ streptomycin $\mathrm{I}^{-1}$, $0.1 \%(\mathrm{w} / \mathrm{v}) \mathrm{BSA}, 2.5 \mathrm{mg}$ transferrin $\mathrm{I}^{-1}, 4 \mu \mathrm{g}$ insulin $\mathrm{I}^{-1}$ and $10 \mu \mathrm{g}$ selenium $\mathrm{I}^{-1}$ ). Follicles were assessed under a dissecting microscope and only those possessing an intact round structure with a centrally located spherical oocyte with intact granulosa cell contacts were used in the study. Initial studies demonstrated that oocytes retrieved from non-cultured $(t=0)$ preantral follicles fulfilling these criteria all scored +++ after vitality staining using 5(6)carboxyfluorescein diacetate (CFSD; Shuttleworth, 2000).

\section{Culture of preantral follicles}

Collagen gel for culture was prepared from rat tails (Torrance et al., 1989) with modifications to allow for serum-free culture (replacing serum with $10 \times$ PBS; E. E. Telfer, personal communication). The inner wells of a 24well culture plate were coated with $250 \mu$ l prepared collagen and placed at $37^{\circ} \mathrm{C}$ for 15 min to set. The wells were washed with four $\times 1 \mathrm{ml} \times 5 \mathrm{~min}$ washes of Way+ at $37^{\circ} \mathrm{C}$ and $5 \% \mathrm{CO}_{2}$ before addition of three $\times 1 \mathrm{ml} \times 5 \mathrm{~min}$ changes with equilibrated follicle culture medium. The culture medium (Way++) was prepared by the addition of $10 \mu \mathrm{g} \mathrm{FSH} \mathrm{I}^{-1}$ (USDA-pFSH-I-2; USDA, Beltsville, MA), 100 $\mu \mathrm{g}$ long R3 IGF-I I-1 (GroPep Pty Ltd, Adelaide) and $0.2 \mathrm{mmol} \mathrm{I}^{-1}$ freshly made ascorbic acid to Way+. Preantral follicles were allocated randomly to treatment groups, placed on top of the collagen base and cultured in groups of three per well, taking care to position the follicles so that they were not in contact with each other. Follicle diameters were measured on day 0 and every subsequent second day by taking two perpendicular measurements and recording the average. At the same time, follicles were assessed for the presence of an antrum and $500 \mu$ of the culture medium was removed and replaced with $500 \mu \mathrm{l}$ fresh, equilibrated medium. Media samples were stored at $-20^{\circ} \mathrm{C}$ for steroid analysis.

\section{Experiment 1: 16 and 30 day culture of follicles in Way++ medium}

Follicles isolated from ovaries from four pigs on two occasions were cultured in Way++ medium to day 16 or 30. On each occasion, 12 follicles were isolated per animal and were assigned randomly to groups to be cultured for 16 or 30 days. A total of 96 follicles was cultured to either day 16 ( $n=48$ follicles, 16 wells) or day 30 ( $n=48$ follicles, 16 wells). At day 14 (16 day culture) or day 28 (30 day culture), the wells containing follicles were randomly divided in half ( $n=24$ follicles, eight wells per group) and testosterone was added to one group only to a final concentration of $100 \mu \mathrm{mol} \mathrm{I}{ }^{-1}$. The other wells had no further supplementation to the replacement medium.

\section{Experiment 2: 16 and 30 day culture of follicles in Way++ medium containing angiotensin II}

Twenty-four follicles were isolated on two occasions from ovaries from two pigs, yielding a total of 96 follicles. Follicles were cultured to day 16 ( $n=48$ follicles, 16 wells in total) or 30 ( $n=48$ follicles, 16 wells in total) to assess the effect of $10^{-10} \mathrm{~mol}$ angiotensin $\mathrm{II} \mathrm{I}^{-1}$ (a physiological concentration; $n=8$ wells per time point) and the effect of 
subsequent testosterone $\left(100 \mu \mathrm{mol} \mathrm{I}^{-1}\right)$ addition at day 14 (16 day culture period; $n=4$ wells per time point) or 28 (30 day culture period; $n=4$ wells per time point). Thus, for each time point (days 16 and 30 of culture), follicles received no supplementation, testosterone supplementation (day 14 or 28, respectively), angiotensin II supplementation alone or supplementation with both angiotensin II and testosterone (day 14 or 28), giving a total of eight different culture conditions at the end of the culture period. Follicles were assigned randomly to these groups with the net result that 12 follicles were cultured under each condition. Therefore, as each well contained three follicles, four wells per culture condition were prepared.

\section{Viability studies}

Oocytes from antral follicles were excised carefully and assessed for viability using CFSD stain. The remaining shell was assessed for viability using the neutral red assay. Follicles that had not developed an antrum were assessed by neutral red assay only as it was not possible to excise an intact oocyte without significant loss of somatic cells from the follicle shell due to mechanical disruption. The procedure for staining the follicle shell with neutral red necessitates the shell remaining as intact as possible to prevent somatic cells being lost during the washing stages, which would affect the number of viable cells assessed by the assay.

Neutral red assay. The number of viable cells per follicle after culture was determined by assessing the uptake of neutral red dye after $3 \mathrm{~h}$ of incubation (Borenfreund and Puerner, 1984; Campbell et al., 1996). Controls comprised 68 oocytes stained in groups of ten, five and two $(n=4$ per group) to assess the impact of the oocyte within preantral follicles on the final calculated number of cells. A further control comprised follicles $(n=12)$ frozen repeatedly at $-20^{\circ} \mathrm{C}$ and thawed, rendering them non-viable, and 12 follicles were also included that had not been stained with neutral red, to determine the background reading. Cell standards comprised granulosa cells collected from pig prepubertal preantral follicles at the time of follicle isolation and maintained in DMEM/F12 medium as described by Picton et al. (1999). Follicles were teased apart using 25G needles to allow homogeneous incubation and treated in situ, taking care to minimize the number of cells lost during the washing steps. Antral follicles were analysed separately from non-antral follicles, as the presence of an antrum would lead to low numbers of cells being reported falsely.

Oocyte viability. CFSD stain was used to assess oocyte viability. Oocytes from antral follicles were isolated, transferred to microdroplets of Way++ containing $5 \mu \mathrm{g}$ CFSD $\mathrm{ml}^{-1}$ at $37^{\circ} \mathrm{C}, 5 \% \mathrm{CO}_{2}$ for $30 \mathrm{~min}$. The oocytes were rinsed in $1 \times \mathrm{PBS}+3 \%(\mathrm{w} / \mathrm{v}) \mathrm{BSA}$, transferred to clean microscope slides and viewed using a fluorescent micro- scope (Olympus Optical Co. Ltd, London) with a L435 filter. Viable cells fluoresce green at $570 \mathrm{~nm}$. Oocytes were given a score from viable $(+++)$ to non-viable (-). Negative controls comprised oocytes that had been isolated and stored in unsupplemented Waymouth medium at $4^{\circ} \mathrm{C}$ for 4 weeks.

Steroid analysis. The concentrations of oestradiol, progesterone and androstenedione were measured using radioimmunoassays as detailed by Grant et al. (1989) and Thomson et al. (1989). Aliquots $(100 \mu \mathrm{l})$ were used to measure progesterone and oestradiol content of the undiluted media samples without prior extraction. Samples taken at days 16 and 30 after addition or non-addition of testosterone were assayed in duplicate and were also assayed for androstenedione. For oestradiol and progesterone assays, the inter- and intra-assay coefficients of variation, and limits of sensitivity were $13.3 \%, 7.4 \%$ and $7.1 \mathrm{pg}$ per tube, and $16.5 \%, 9.4 \%$ and 6.0 pg per tube, respectively. For the androstenedione assay, the intra-assay variation was $8.7 \%$ and the limit of sensitivity was $5.1 \mathrm{pg}$ per tube. Samples from wells containing antral follicles were analysed separately from wells in which no follicles contained an antrum to determine whether the presence of an antrum was exerting an effect on steroid synthesis.

\section{Statistical analysis}

Changes in follicle diameter and steroid composition were analysed by ANOVA modified for repeated measures on Genstat for Windows computer package (Genstat 5, Third Edition, Release 4.1). Pooled variance was used to calculate the standard error of the difference (SED) between means. For all analyses, effects were considered significant at $P<0.05$. Differences in determined number of cells between days 0,16 and 30 of culture were analysed using the Kruskal-Wallis one-way ANOVA by ranks. Further post hoc analysis between sample groups was completed using Mann-Whitney $U$ test. The proportion of follicle degeneration or antrum formation, and the proportion of oocytes determined as viable using CFSD were analysed using the chi-squared test.

\section{Results}

\section{Experiment 1: 16 and 30 day culture of follicles in} Way++ medium

Changes in follicle diameter and number of somatic cells, and an example of oocytes stained with CFSD are shown (Fig. 1a, Fig. 1b,c and Fig. 2, respectively). Follicle diameter increased significantly $(P<0.001)$ over both 16 and 30 days of culture. Over 16 days of culture, 12 follicles $(25 \%)$ formed antra (three in one well, two in three wells and one in three wells) and two follicles (one antral, one non-antral) from different wells appeared to have degenerated towards the end of culture. These were not assayed for number of viable cells, as they could not be 

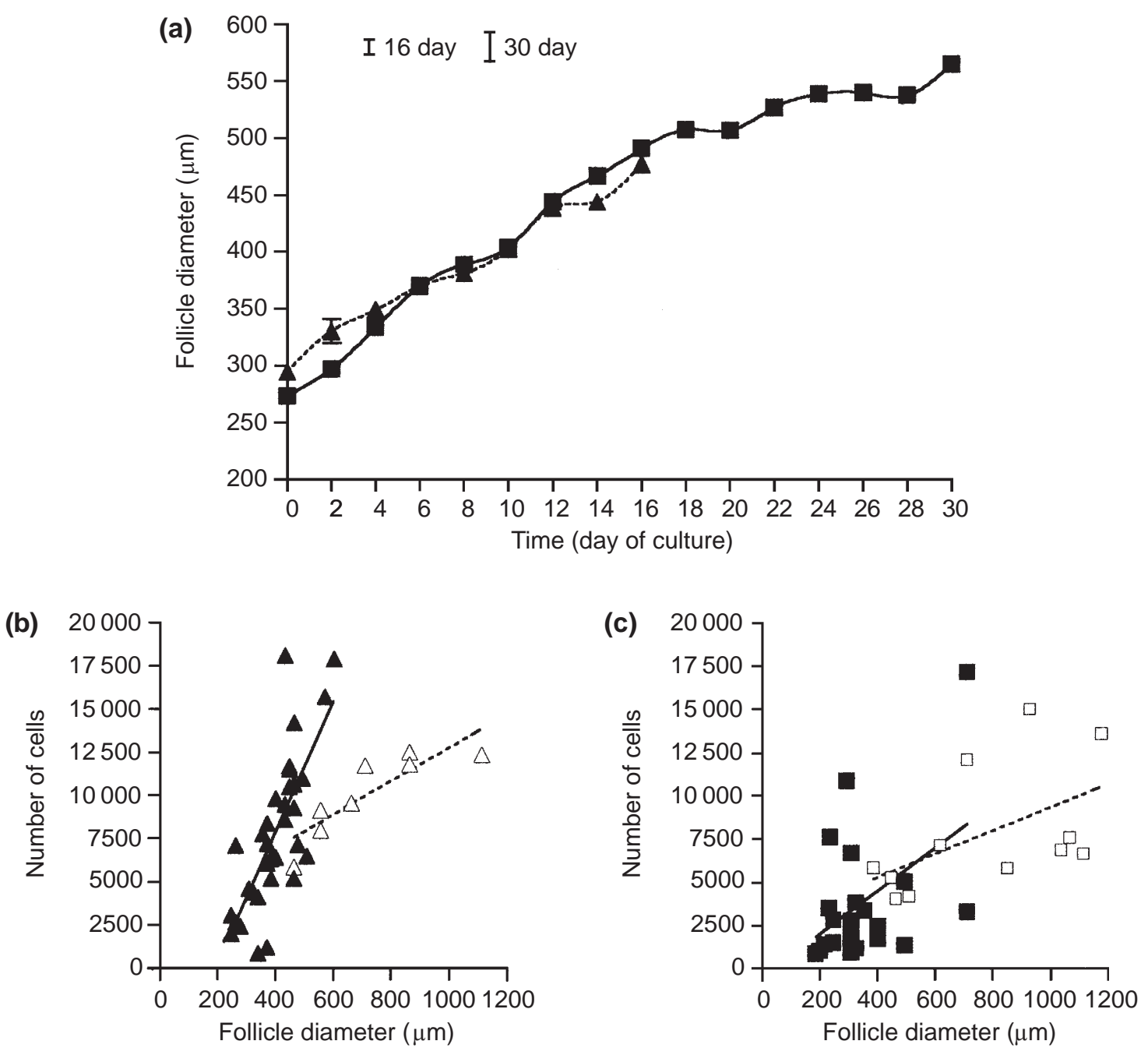

Fig. 1. (a) Diameter of pig follicles cultured for 16 days $(\boldsymbol{\Lambda}: n=48)$ and 30 days $(\boldsymbol{\square}: n=48)$ in serum-free medium. Number of somatic cells, as determined by neutral red analysis, of pig follicles cultured for (b) 16 days ( $\mathbf{\Lambda}$ : nonantral follicles, $n=35$; $\triangle$ : antral follicles, $n=8$ ) and (c) 30 days ( $\square$ : non-antral follicles, $n=29$; $\square$ : antral follicles, $n=12)$. Follicle diameter increased significantly $(P<0.001)$ over both 16 and 30 days of culture. Error bars in (a) are SEDS between different time points.

removed from culture. A further three antral follicles were damaged when removed from culture and some somatic cells were lost; these three follicles were not assayed for number of viable cells, although it was possible to retrieve the oocyte for CFSD staining. Therefore, it was possible to assay 35/36 non-antral and 8/12 antral follicles for number of viable cells (Fig. 1b). The oocytes from the 12 antral follicles were deemed viable using CFSD (eight scored +++; four scored ++; none scored +; none scored -).

Over 30 days of culture, 14 follicles formed antra (29\%; three in two wells, two in one well and six in separate wells: 12 were retrievable for neutral red assessment) and nine follicles from separate wells appeared degenerate (two antral and seven non-antral follicles). Two of the non-antral follicles that appeared degenerate on day 26 were included for assay for cell viability; the other seven degenerate follicles could not be retrieved for assay. Therefore, it was possible to assay 29/34 non-antral and 12/14 antral follicles for number of viable cells (Fig. 1c). Oocytes from all antral follicles were available for CFSD staining, including those that appeared degenerate. These were included as the follicles had only started showing signs of degeneration at days 24 and 26, and although it was not possible to remove the shell from culture, it was possible to excise the oocyte. However, both of these oocytes only scored + . In total, five scored +++ , three scored ++ , six scored + and none scored -.

Oestradiol secretion did not begin to increase until day 14 during both 16 day (data not shown as there was no increase) and 30 day culture periods (Fig. 3). The increase 

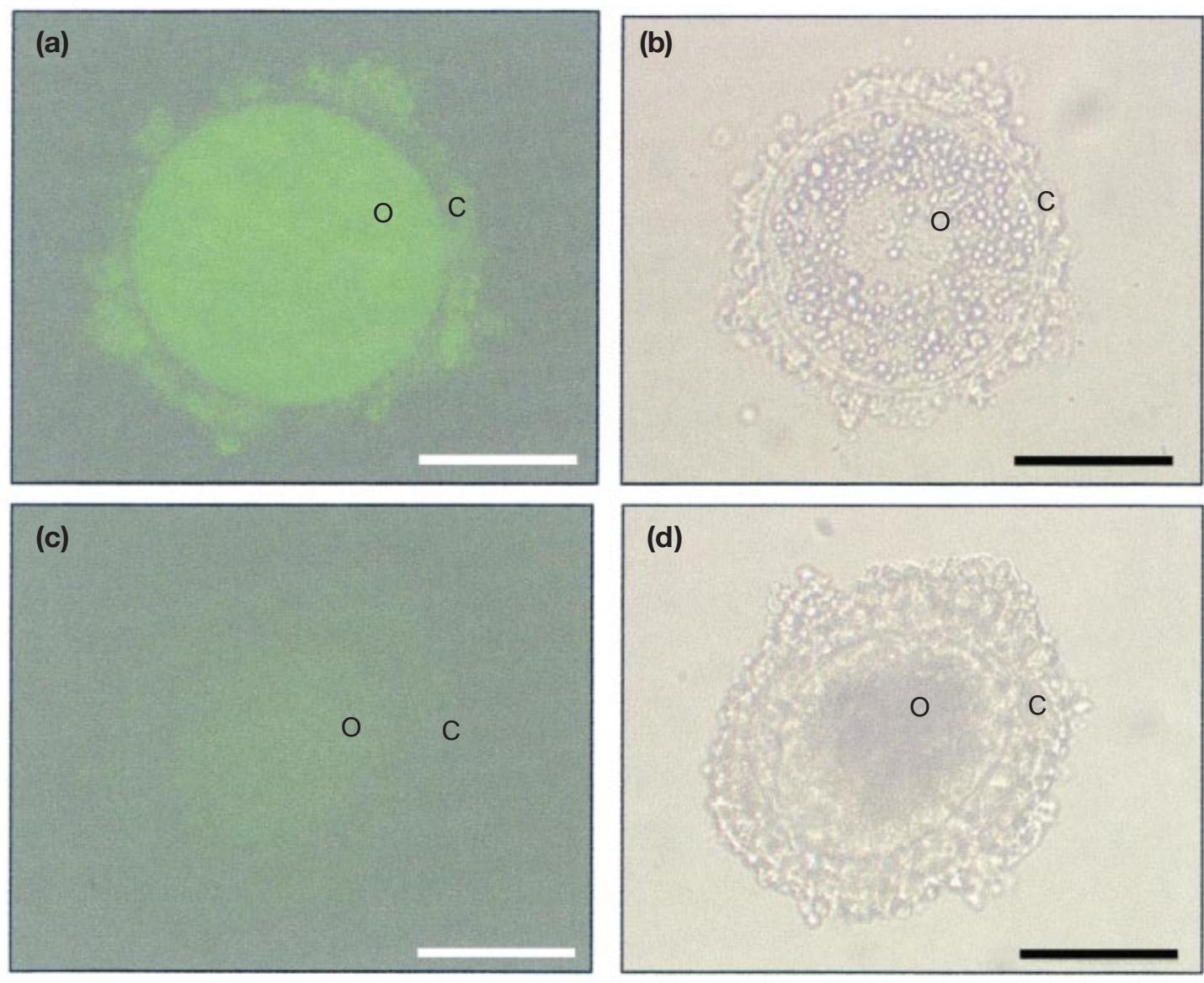

Fig. 2. Images of $(a, b)$ a viable and $(c, d)$ a non-viable pig oocyte stained with 5(6)-carboxyfluorescein diacetate (CFSD) under $(\mathrm{a}, \mathrm{c})$ fluorescent light and $(\mathrm{b}, \mathrm{d})$ normal light. a: score +++ ; $\mathrm{c}$ : score - . Note the dark centre of the non-viable oocyte compared with the healthy oocyte. O: oocyte; C: cumulus cells. Scale bars represent $50 \mu \mathrm{m}$.

was subsequently maintained and was significant over time $(P<0.001 ; 30$ day culture). The presence of an antrum did not result in a further significant difference in oestradiol secretion. Addition of testosterone at days 14 and 28 resulted in highly significant $(P<0.001)$ increases in oestradiol secretion on days 16 and 30 , respectively, by follicles compared with secretion at days 14 and 28 (Fig. $3 a-c)$. Further analysis using the Mann-Whitney $U$ test revealed that there was a significant difference (day 16, $P<0.05$ : day $30, P<0.001)$ when comparing wells without testosterone addition or antrum formation with wells in which there was both testosterone addition and antrum formation. However, at day 30, there was a significant effect of addition of testosterone versus non-addition of testosterone on both antral $(P<0.01)$ and preantral $(P<0.05)$ follicles. When considering progesterone secretion (data not shown), there appeared to be a significant increase in secretion by antral follicles $(P<0.001)$ over 14 days of culture, which was maintained to day 28 of culture. There was also a significant increase $(P<0.01)$ in progesterone secretion after testosterone addition at days 16 and 30, although inspection of these data using the Mann-Whitney $U$ test revealed no further interactions.

\section{Experiment 2: 16 and 30 day culture of follicles in Way++ medium containing angiotensin II}

There was a significant $(P<0.001)$ increase in follicle diameter with time (Fig. 4a). However, there was no significant effect on growth with the addition of angiotensin II to the culture media over 16 or 30 days of culture (although there appeared to be an increasing trend towards increased follicle diameter with angiotensin II addition over 30 days of culture). As there was no significant effect over 16 days of culture, these data are not shown. Antrum formation was observed only in follicles $>400 \mu \mathrm{m}$ in diameter. Over 16 days of culture, only the follicles cultured without angiotensin II developed antra $(n=12: P<0.001)$ and one follicle from each condition deteriorated. All oocytes were retrieved from antral follicles and stained 


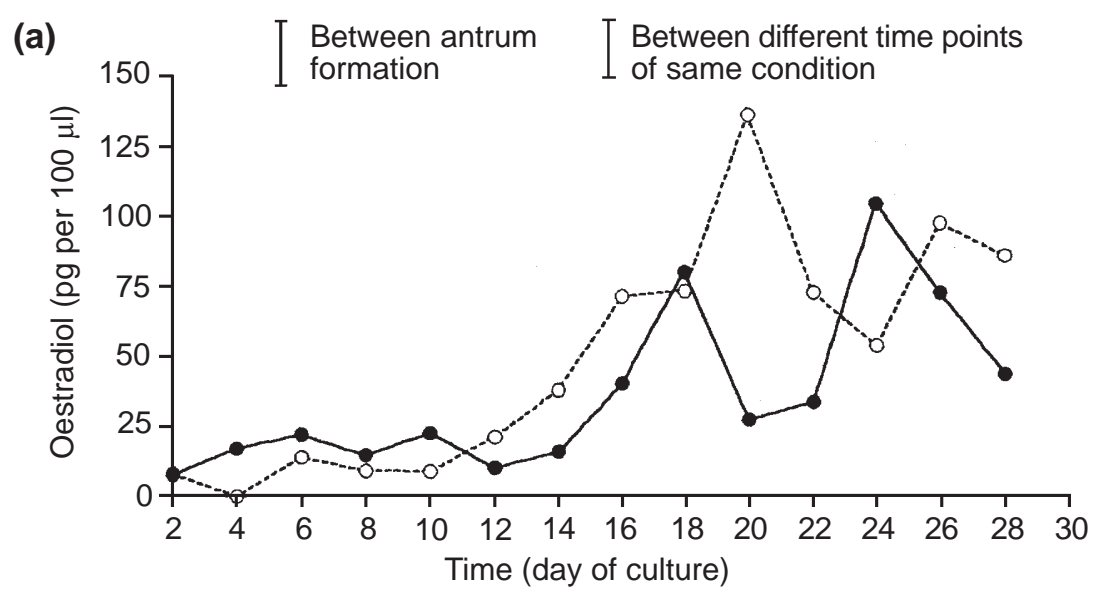

(b)

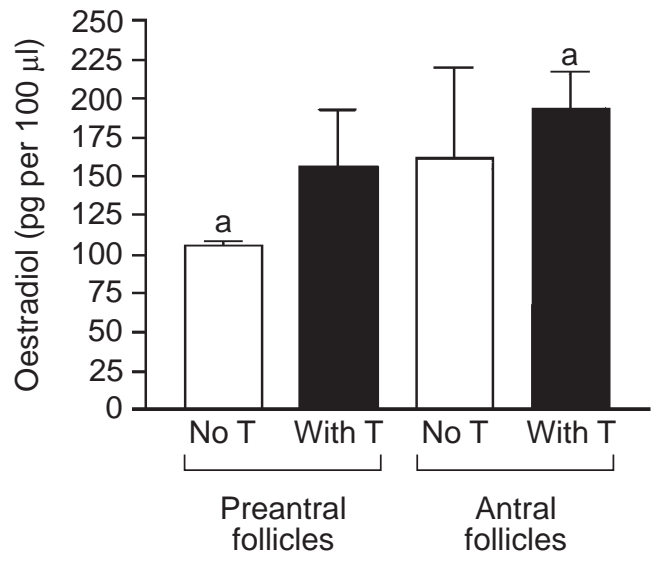

(c)

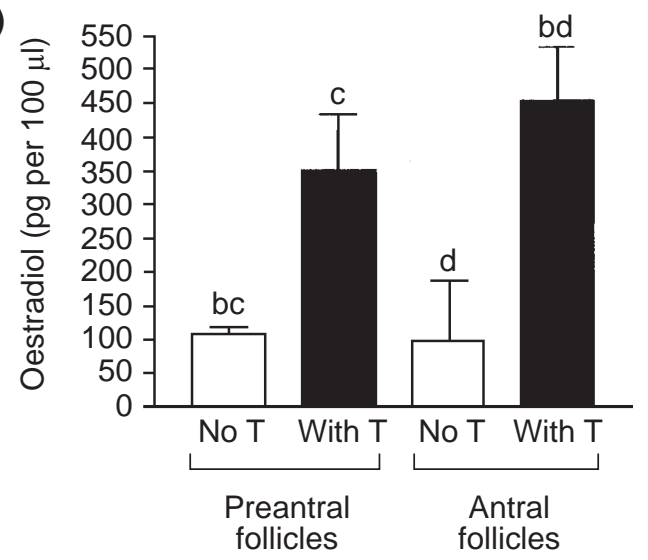

Fig. 3. (a) Oestradiol secretion over 30 days of culture in wells containing three pig follicles that have not formed an antrum $(-)$ or at least one of which has formed an antrum $(\bigcirc)$. Over 30 days of culture, there was a significant increase in oestradiol secretion $(P<0.001)$. (b,c) Effect of addition of testosterone $\left(T ; 100 \mathrm{mmol}^{-1}\right)$ to wells containing pig preantral follicles or at least one antral follicle at (b) day 16 and (c) day 30. Error bars in (a) are SEDS, $n=3-5$ per group. There was a significant increase in oestradiol secretion after addition of testosterone $(P<0.001)$.

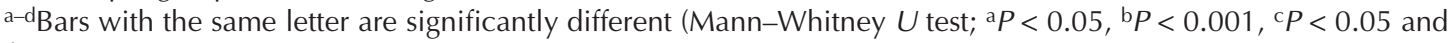
$\mathrm{d} P<0.01)$.

with CFSD; six scored +++, four scored ++, two scored + and none scored - . Over 30 days of culture, 11 follicles cultured with angiotensin II and seven follicles cultured without angiotensin II developed antra (not significant), and three and two follicles, respectively, deteriorated. When considering the viability of oocytes, 5/11 oocytes retrieved from follicles cultured with angiotensin II scored +++ compared with 2/7 of those cultured without angiotensin II. Of the remaining follicles cultured with angiotensin II, one oocyte scored ++ , four scored + and none scored - . Of the oocytes from follicles cultured without angiotensin II, two had a CFSD score of ++ , three had a score of + and none had a score of -. The addition of angiotensin II at both time points resulted in no significant change in the number of viable cells per follicle diameter compared with follicles cultured without angiotensin II (Fig. 4b,c).

Oestradiol secretion increased markedly after 10 days, although the increase was only significant $(P<0.001)$ over 30 days of culture (Fig. 5a). Addition of $10^{-10} \mathrm{~mol}$ angiotensin $\mathrm{II} \mathrm{I}^{-1}$ did not result in a significant change in oestradiol secretion above control values. When testosterone was added with or without angiotensin II, there was an increase in oestradiol secretion in all cases (Fig. 5b,c) although it was only possible to analyse this between preantral follicles cultured with angiotensin II to day 16 $(P<0.01)$. There appeared to be an increasing trend reflecting this at day 30 between preantral and antral follicles cultured with or without angiotensin II, indicating that angiotensin II may exert an effect on testosterone in increasing oestradiol secretion.

Progesterone secretion assessed over 30 days of culture did not increase until day 16 (with an antrum) or day 26 (without an antrum), although there was a significant increase with time over 30 days of culture $(P<0.01$; Fig. 5 d). 

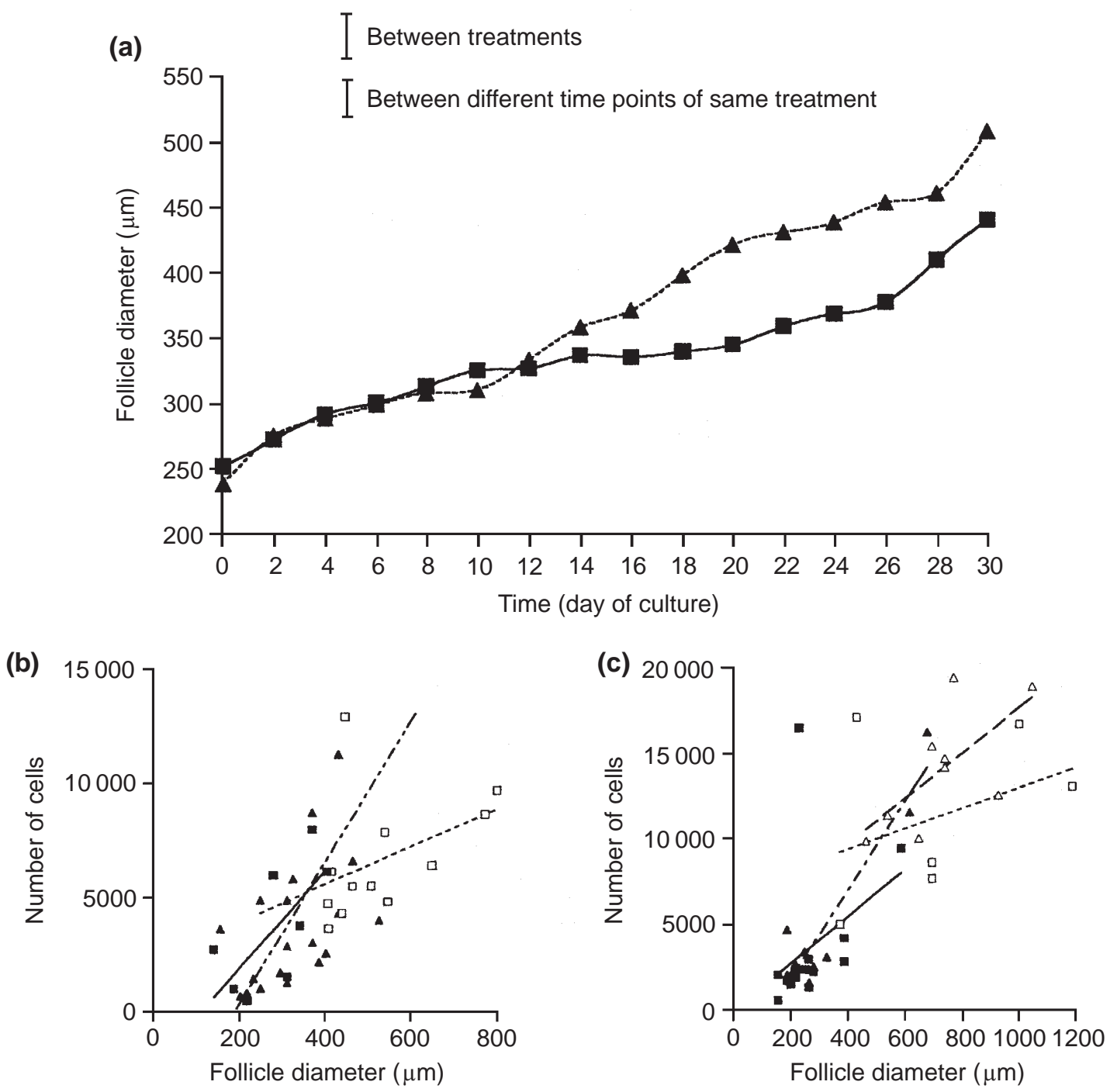

Fig. 4. (a) Diameter of pig follicles cultured with $(\mathbf{A})$ and without $(\boldsymbol{\square}) 10^{-10} \mathrm{~mol}$ angiotensin II I-1 for 30 days $(n=24$ per group: $P<0.001)$. Number of somatic cells, as determined by neutral red analysis, of pig follicles cultured with or without angiotensin II to (b) day 16 or (c) day 30, both with and without antrum formation ( $\mathbf{\Lambda}$ : with angiotensin II, no antrum, $n=21$ (day 16) or $n=12$ (day 30); $\triangle$ : with angiotensin II, with antrum, $n=0$ (day 16) or $n=9$ (day 30); $\mathbf{\square}$ : no angiotensin II, no antrum, $n=9$ (day 16) or $n=15$ (day 30); $\square$ : no angiotensin II, with antrum, $n=12$ (day 16 ) or $n=6$ (day 30$)$ ).

At day 16 of culture (Fig. 5e), in preantral follicles, both angiotensin II and testosterone were required to elicit a significant $(P<0.01)$ increase in progesterone secretion with addition of testosterone. It was not possible to analyse the effect of angiotensin II and the presence of an antrum on the effect of testosterone at day 16 , as there were no antral follicles present. However, at day 30 (Fig. 5f), the combination of antral follicles cultured in testosterone and angiotensin II showed the highest synthesis, although this could not be analysed due to large inter-individual variation.

The concentrations of androstenedione were below the limit of detection and so are not reported. In all experiments, the incidence of follicular degeneration did not differ between treatments.

\section{Discussion}

In the present study, data indicating a serum-free medium suitable for the long-term culture of pig preantral follicles that was suitable for testing the effects of angiotensin II on early follicle development in culture are presented.

The in vitro development of antral follicles has been extremely successful in mice (Spears et al., 1994), although this is facilitated by the small size of the follicle at ovulation 

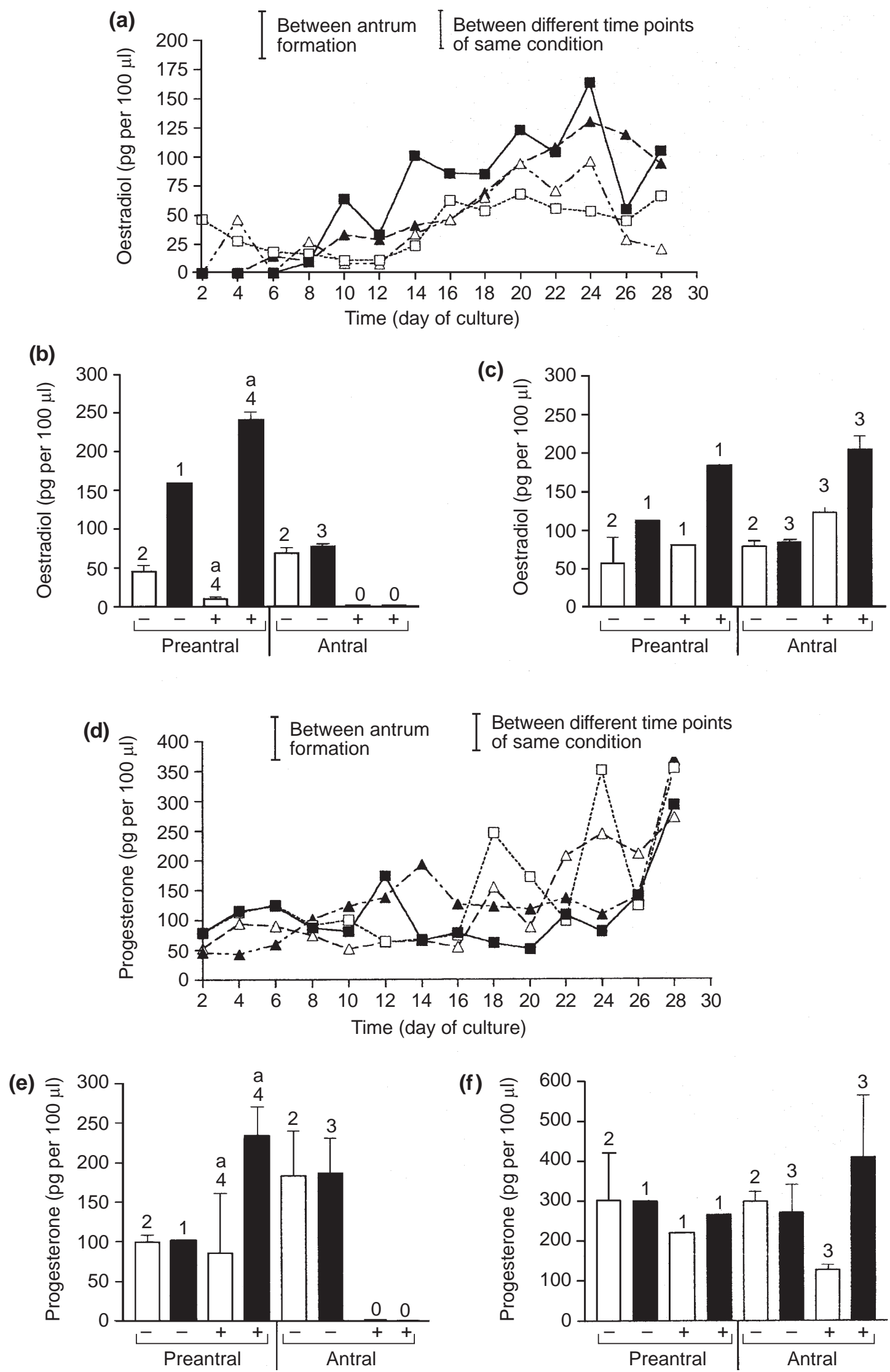

Fig. 5. For legend see facing page. 
and the short time ( 6 days) required for preantral follicles to reach Graafian follicle status in vitro. Follicles from larger domestic species require much longer periods of time to develop to antral stages in vivo, which may also be expected in vitro. Success is reported in the present study in which culture conditions were based on those developed for the serum-free culture of pig granulosa cells (Picton et al., 1999). This strategy has also been used for culture of bovine preantral follicles (Gutiérrez et al., 1997, 2000). In the present study, follicles increased in diameter by approximately $150 \mu \mathrm{m}$ over 16 days and $300 \mu \mathrm{m}$ over 30 days of culture, which is comparable to the results of Gutiérrez et al. (2000). However, Gutiérrez et al. (2000) reported that $55 \%$ of follicles formed an antrum, although fewer were cultured to 28 days than in the present study. Culture of ovine granulosa-oocyte complexes (GOCs), which lack a basement membrane and thecal cell layer, in serum-free media showed much larger increases putatively as a result of the lack of a restrictive basement membrane, and $25 \%$ formed an antrum (Newton et al., 1999). Our data show that $25-29 \%$ of follicles cultured in Way++ developed an antrum, which is an improvement on previous studies using pigs in which only $19 \%$ formed an antral cavity (Hirao et al., 1994). Hirao et al. (1994) demonstrated that follicles increased in size two- to threefold over 16 days of culture, potentially as a result of the lack of a restrictive thecal layer surrounding follicles in their culture system, but possibly also as a result of the addition of a further undefined element in the serum used in the culture protocol. A more recent study in which serum was used reported an $87 \%$ rate of antrum formation despite the fact that a thecal layer was present (Wu et al., 2001). These results, together with those of the present study and the study of Hirao et al. (1994), indicate the importance of retaining thecal cells in culture of pig preantral follicles.

In the present study, antrum formation was not detected until approximately day 10 of culture and only when follicles were $>400 \mu \mathrm{m}$ in diameter. This size is in agreement with development in vivo as demonstrated in previous histological studies in pigs (Morbeck et al., 1992) and is also in agreement with the results of Wu et al. (2001). Previous studies in vitro on preantral follicles showed antrum formation at day 10 in cows (Gutiérrez et al., 2000), days 6-8 in pigs (Donnelly and Telfer, 1994) and day 13 in ovine GOCs (Newton et al., 1999). These time scales are all comparable to those observed in the present study and may represent the effect of a period of adjust- ment required by follicles after isolation. However, it has been reported by Wu et al. (2001) that antrum formation in cultured pig preantral follicles may occur in as few as 2 days. This may be a factor of using a serum-based system or a result of the smaller volumes of media used for culture $(280 \mu \mathrm{l})$, thereby increasing the net concentration of any secreted factor involved in stimulating antrum formation.

Formation of an antrum in one follicle of the three per well did not suppress antrum formation in the other follicles. It has been suggested that murine follicles may secrete a diffusible inhibitory factor (Baker et al., 1999). If such a diffusible factor is responsible for antrum suppression in pig follicles, it may have been at too low a concentration to be effective in the culture system used in the present study and would have been impaired further by the deliberate lack of contact between follicles in culture. Spears et al. (1996) demonstrated that follicles cultured in close proximity would co-join and develop a shared thecal layer. Although this extent of clustering was not observed in the present study, it was noted that although follicles were placed as far away from each other as possible within the well, they frequently appeared to 'grow' towards each other. Thus, although the follicles are not exerting an inhibitory effect on their neighbours, they may be secreting a factor encouraging growth towards each other. In a recent pig follicle culture experiment, it was contended that the optimum number of pig follicles in culture is three, which may be a result of optimization of potential interfollicular secretion in much smaller media volumes than those used in the present study (Wu et al., 2001).

The amounts of oestradiol synthesized over 28 days in Way++ medium reached a maximum of 136 pg per $100 \mu \mathrm{l}$ per $48 \mathrm{~h}$, and progesterone synthesis reached a maximum of $168 \mathrm{pg}$ per $100 \mu \mathrm{l}$ per $48 \mathrm{~h}$. In support of the concept of 'settling in' time required by follicles, it is apparent that increased oestradiol synthesis occurred after day 14 of culture. In comparison with culture of human follicles, oestradiol secretion was tenfold higher and showed an increase over time that was not observed in cultures of human follicles even though the medium was replaced once a week (Abir et al., 1997). Earlier studies culturing human preantral follicles for 5 days demonstrated an increase in oestradiol, progesterone and androstenedione up to rates of $0.25 \mathrm{pg}$ per follicle per day, $75 \mathrm{pg}$ per follicle per day and 3 pg per follicle per day, respectively (Roy and Treacy, 1993). As in the present study, more progesterone

Fig. 5. $(a, b, c)$ Oestradiol and $(d, e, f)$ progesterone secretion over $(a, d) 28$ days of culture, and (b,c,e,f) on day 30 after testosterone addition or non-addition. Oestradiol secretion increased significantly over 30 days of culture $(P<0.001)$, as did progesterone secretion $(P<0.01)$. Over the 28 days of culture, follicles were cultured with (+) or without (-) angiotensin II in wells containing three follicles that had either not formed an antrum (preantral: $\mathbf{\Delta}$ : with angiotensin II, $n=2$ wells; $\mathbf{\square}$ : no angiotensin II, $n=3$ wells) or in wells in which at least one follicle had formed an antrum (antral: $\triangle$ : with angiotensin II, $n=6$ wells: $\square$ : no angiotensin II, $n=5$ wells). These groups were divided and the effect of addition of testosterone (with $100 \mathrm{mmol}$ testosterone $\mathrm{I}^{-1}$ : black column; no additional testosterone: open column) on (b,c) oestradiol and $(\mathrm{e}, \mathrm{f})$ progesterone secretion at $(\mathrm{b}, \mathrm{e})$ day 16 and $(\mathrm{c}, \mathrm{f})$ day 30 is compared. Values corresponding to the resulting number of wells analysed per condition are indicated $(\mathrm{b}, \mathrm{c}, \mathrm{e}, \mathrm{f})$. Where $n=2$, the error bars indicate range. ${ }^{\text {Bars }}$ with the same letter are significantly different $(P<0.01)$. 
than oestradiol was synthesized and concentrations of androstenedione were low, which may indicate that, although we were unable to demonstrate the presence of androstenedione in the media in our system, this may be a result of a dilution effect. The lack of a measurable concentration of androstenedione in the present study might also be a result of rapid conversion of this steroid to oestradiol under these culture conditions.

The addition of testosterone to follicles cultured in Expt 1 resulted in a significant increase in oestradiol but not progesterone secretion. Antral GOCs supplemented with testosterone secreted oestradiol (approximately $2.4 \mathrm{ng} \mathrm{ml}^{-1}$ ) at a comparable rate to that reported in the present study even without further testosterone supplementation (Newton et al., 1999). In the present study, isolated follicles possessed a thecal cell layer and it was expected that these cells would provide additional substrate to the granulosa cells. The results indicate that although they provided some substrate, further testosterone supplementation resulted in a significant increase in oestradiol secretion. Thus, a fine balance must be reached between isolating sufficient numbers of thecal cells to enable steroid synthesis while also maintaining follicular growth, which may benefit from reduced numbers of thecal cells at the same time as being detrimental to antrum formation (Hirao et al., 1994). However, if it is deduced from the neutral red results that each follicle possessed approximately 10000 cells, then the amount of oestradiol secreted per follicle in each experiment is comparable to the amount secreted per 10000 pig granulosa cells in culture (Picton et al., 1999). This result indicates that there is a functioning steroid cascade within the granulosa cell layer of the cultured follicles and also that they are responding to the same supplements as those used by Picton et al. (1999).

In initial studies (Shuttleworth, 2000), culturing follicles with high concentrations $\left(10^{-8} \mathrm{~mol} \mathrm{I}^{-1}\right)$ of angiotensin II resulted in an increase in the number of somatic cells per unit follicle diameter as determined by neutral red analysis. This may be due to an increase in granulosa cell proliferation that is not matched by synthesis of basement membrane, even though the medium was supplemented with the ascorbic acid necessary for membrane remodelling (Murray et al., 2001). Culture for 30 days with angiotensin II in the present study resulted in a small increase in follicle diameter above that observed without angiotensin II, although this increase was not significant. This trend was not observed initially over 16 days of culture, which may be due to the hypothesized resting period. Furthermore, culture with angiotensin II to day 16 did not result in any follicles forming an antrum, in contrast to those cultured without angiotensin II, although these follicles possessed more somatic cells per unit follicle diameter. This finding indicates that angiotensin II may stimulate the division of granulosa cells, with the result that antra do not form, and is in contrast to a previous study which indicated that FSHresponsive pig granulosa cells were not responsive to angiotensin II (Flores et al., 1991).
Long-term culture with angiotensin II resulted in rates of oestradiol and progesterone synthesis comparable to those observed without angiotensin II supplementation. This finding is in contrast to previous studies in which pig granulosa cells were cultured with serum, and angiotensin II was shown to inhibit steroidogenesis by interacting with the $3 \beta$-hydroxysteroid dehydrogenase (3ß-HSD) gene or mRNA stability (Li et al., 1995). Studies on bovine luteal cells indicate that angiotensin II may act earlier in the steroid cascade by inhibiting the cholesterol side chain cleavage enzyme responsible for the conversion of cholesterol to pregnenolone (Stirling et al., 1990). In the present study, it does not appear that angiotensin II is having an effect on these components. Studies in rats have demonstrated that angiotensin II did not affect aromatase activity and progesterone concentrations (Pucell et al., 1988). However, in a recent study perfusion of bovine antral follicles with $10^{-5}$ mol angiotensin II I-1 (a high non-physiological concentration) resulted in an increase in both progesterone and oestradiol concentrations (Acosta et al., 1999). In the present study, angiotensin II concentrations were much lower $\left(10^{-10} \mathrm{~mol} \mathrm{I}^{-1}\right)$ and the discrepancy may be due to this as well as to species differences. However, addition of testosterone at days 14 and 28 resulted in significant increases in oestradiol secretion when angiotensin II was present, which was enhanced further by the presence of an antrum. This was not observed when progesterone secretion at day 30 is considered, although there were trends comparable to oestradiol secretion at day 16 by preantral follicles. It may be that the initial effect of angiotensin II is in the control of progesterone synthesis. This would correspond with the 'resting period' and, once the follicles resume growth, angiotensin II may switch to emphasizing oestradiol synthesis and stimulating aromatase action. Pepperell et al. (1994) proposed such a biphasic action of angiotensin II on the action of aromatase. It must also be considered that follicles are secreting angiotensin II in addition to the angiotensin II supplementing the medium, and also that the culture media contains insulin-like growth factor I (IGF-I), which has been suggested to enhance ovarian angiotensin II production further (Yoshimura et al., 1996). These two factors would increase the overall concentration in the culture medium.

In conclusion, the results of the present study demonstrate that a serum-free medium is suitable for the long-term culture of pig preantral follicles. The follicles synthesized measurable quantities of oestradiol and progesterone. Furthermore, this culture system was effective for testing the influence of other compounds on follicular development. Addition of $10^{-10}$ mol angiotensin II I-1 stimulated increases in the number of somatic cells and steroid synthesis, and provides evidence for the presence and function of an active pig ovarian renin-angiotensin system.

The authors would like to thank V. Brankin for kindly completing the androstenedione assay. 


\section{References}

Abir R, Franks S, Mobberley MA, Moore PA, Margara RA and Winston RML (1997) Mechanical isolation and in vitro growth of preantral and small antral human follicles Fertility and Sterility $\mathbf{6 8}$ 682-688

Acosta TJ, Berisha B, Ozawa T, Sato K, Schams D and Miyamoto A (1999) Evidence for a local endothelin-angiotensin-atrial natriuretic peptide system in bovine mature follicles in vitro: effects on steroid hormones and prostaglandin secretion Biology of Reproduction 61 1419-1425

Amorim CA, Lucci CM, Rodrigues APR et al. (2000) Quantitative and qualitative analysis of the effectiveness of a mechanical method for the isolation of preantral follicles from ovine ovaries Theriogenology 53 $1251-1262$

August P and Sealey JE (1990) The renin-angiotensin system in normal and hypertensive pregnancy and in ovarian function. In Hypertension: Pathophysiology, Diagnosis and Management pp 1761-1778 Eds JH Laragh and BM Brenner. Raven Press Ltd, New York

Baker SJ, Mullan J, Lapping R, Nelson RJ, Allison V and Spears N (1999) A diffusible factor produced by late pre-antral follicles inhibits the growth of similarly sized follicles in vitro. Biology of Reproduction $\mathbf{6 0}$ (Supplement 1) 574 (Abstract)

Borenfreund E and Puerner JA (1984) A simple quantitative procedure using monolayer cultures for cytotoxicity assays (HTD/NR-90) Journal of Tissue Culture Methods 9 7-9

Campbell BK, Scaramuzzi RJ and Webb R (1996) Induction and maintenance of oestradiol and immunoreactive inhibin production with FSH by ovine granulosa cells cultured in serum-free media Journal of Reproduction and Fertility 106 7-16

Cecconi S, Barboni B, Coccia M and Mattioli M (1999) In vitro development of sheep preantral follicles Biology of Reproduction $\mathbf{6 0}$ 594-601

Donnelly K and Telfer EE (1994) Growth of porcine preantral ovarian follicles in different culture systems Journal of Reproduction and Fertility Abstract Series 13 Abstract 27

Figueiredo JR, Hulshof SCJ, van den Hurk R, Nusgens B, Bevers MM, Ectors FJ and Beckers JF (1994) Preservation of oocyte and granulosa cell morphology in bovine preantral follicles cultured in vitro. Theriogenology 41 1333-1346

Flores JA, Veldhuis JD and Leong DA (1991) Angiotensin II induces calcium release in a subpopulation of single ovarian (granulosa) cells Molecular and Cellular Endocrinology 81 1-10

Flowers WL and Turner ZA (1996) In vitro growth of preantral follicles isolated from prepubertal gilts Journal of Animal Science $\mathbf{7 4}$ (Supplement 1) 220

Grant SA, Hunter MG and Foxcroft GR (1989) Morphological and biochemical characteristics during ovarian follicular development in the pig Journal of Reproduction and Fertility 86 171-183

Greenwald GS (1994) Enzymatic dissociation of the mammalian ovary to recover primordial and pre-antral follicles Human Reproduction 9 973-974

Gutiérrez CG, Campbell BK and Webb R (1997) Development of a long-term bovine granulosa cell culture system: induction and maintenance of estradiol production, response to follicle-stimulating hormone, and morphological characteristics Biology of Reproduction $\mathbf{5 6} 608-616$

Gutiérrez CG, Ralph JH, Telfer EE, Wilmut I and Webb R (2000) Growth and antrum formation of bovine preantral follicles in long-term culture Biology of Reproduction 62 1322-1328

Hagemann A, Nielsen AH, Dantzer V, Avery B and Poulsen K (1992) Measurement and identification of prorenin and renin in ovarian follicular fluid from cattle and pig Clinical and Experimental Pharmacology and Physiology 19 267-273

Hartshorne GM (1997) In vitro culture of ovarian follicles Reviews of Reproduction 2 94-104

Hirao Y, Nagai T, Kubo M, Miyano T, Miyake M and Kato S (1994) In vitro growth and maturation of pig oocytes Journal of Reproduction and Fertility $100333-339$

Hulshof SCJ, Figueiredo JR and Beckers JF (1994) Isolation and characterisation of pre-antral follicles from bovine ovaries Veterinary Quarterly 16 78-80

Levy BI (1998) The potential role of angiotensin II in the vasculature Journal of Human Hypertension 12 283-287

Li XM, Juorio AV and Murphy BD (1995) Angiotensin II interferes with steroidogenesis in porcine granulosa cells Biology of Reproduction $\mathbf{5 3}$ 791-799

Morbeck DE, Sebenshade KL, Flowers WL and Britt JH (1992) Kinetics of follicle growth in the prepubertal gilt Biology of Reproduction 47 485-491

Murray AA, Molinek MD, Baker SJ, Kojima FN, Smith MF, Hillier SJ and Spears N (2001) Role of ascorbic acid in promoting follicle integrity and survival in intact mouse ovarian follicles in vitro. Reproduction $\mathbf{1 2 1}$ 89-96

Nayudu PL and Osborn SM (1992) Factors influencing the rate of preantral and antral growth of mouse ovarian follicles in vitro. Journal of Reproduction and Fertility 95 349-362

Newton H, Picton H and Gosden RG (1999) In vitro growth of oocyte-granulosa cell complexes isolated from cryopreserved ovine tissue Journal of Reproduction and Fertility 115 141-150

Nielsen AH, Hagemann A, Avery B and Poulsen K (1995) Differences in expression of angiotensin II receptors and renin in porcine and bovine ovaries Experimental and Clinical Endocrinology and Diabetes 103 332-338

Pepperell JR, Nemeth G, Roa L, Yamada Y, Palumbo A and Naftolin F (1994) Intraovarian regulation by the ovarian renin-angiotensin system Australian and New Zealand Journal of Obstetrics and Gynaecology 34 288-292

Picton HM, Campbell BK and Hunter MG (1999) Maintenance of oestradiol production and expression of cytochrome P450 aromatase enzyme mRNA in long-term serum-free cultures of pig granulosa cells Journal of Reproduction and Fertility 115 67-77

Pucell AG, Bumpus FM and Husain A (1988) Regulation of angiotensin II receptors in cultured rat ovarian granulosa cells by follicle-stimulating hormone and angiotensin II Journal of Biological Chemistry 263 11 954-11961

Qvist R, Blackwell LF, Bourne H and Brown JB (1990) Development of mouse ovarian follicles from primary to preovulatory stages in vitro. Journal of Reproduction and Fertility 89 169-180

Roy SK and Treacy BJ (1993) Isolation and long-term culture of human preantral follicles Fertility and Sterility $\mathbf{5 9}$ 783-790

Saha S, Shimizu M, Geshi M and Izaike Y (2000) In vitro culture of bovine preantral follicles Animal Reproduction Science 63 27-39

Shores EM, Picton HM and Hunter MG (2000) Differential regulation of pig theca cell steroidogenesis by $\mathrm{LH}$, insulin-like growth factor 1 and granulosa cells in serum-free culture Journal of Reproduction and Fertility 118 211-219

Shuttleworth G (2000) Porcine Ovarian Follicle Development and the Renin-Angiotensin System PhD Thesis, University of Nottingham

Shuttleworth G, Hunter MG and Broughton Pipkin F (2001) Autoradiographic determination of angiotensin ॥ receptors in prepubertal and postpubertal porcine ovarian tissue Reproduction 122 $701-710$

Spears N, Boland NI, Murray AA and Gosden RG (1994) Mouse oocytes derived from in vitro grown primary ovarian follicles are fertile Human Reproduction 9 527-532

Stirling D, Magness RR, Stone R, Waterman MR and Simpson ER (1990) Angiotensin II inhibits luteinizing hormone-stimulated cholesterol side chain cleavage expression and stimulates basic fibroblast growth factor in bovine luteal cells in primary culture Journal of Biological Chemistry 265 5-8

Telfer EE (1996) The development of methods for isolation and culture of preantral follicles from bovine and porcine ovaries Theriogenology 45 $101-110$

Telfer EE (1998) In vitro models for oocyte development Theriogenology 49 $451-460$

Thomson S, Wallace AM and Cook B (1989) A ${ }^{125}$-radioimmunoassay for measuring androstenedione in serum and in blood-spot samples from neonates Clinical Chemistry 35 1706-1712 
Torrance C, Telfer E and Gosden RG (1989) Quantitative study of the development of isolated mouse pre-antral follicles in collagen gel culture Journal of Reproduction and Fertility 87 367-374

Wu J, Emery BR and Carrell DT (2001) In vitro growth, maturation, fertilization and embryonic development of oocytes from porcine preantral follicles Biology of Reproduction 64 375-381

Yoshimura Y, Aoki N, Sueoka K, Miyazaki T, Kuji N, Tanaka M and Kobayashi T (1996) Interactions between insulin-like growth factor-I
(IGF-I) and the renin-angiotensin system in follicular growth and ovulation Journal of Clinical Investigation 98 308-316

Received 11 October 2001

First decision 4 December 2001.

Revised manuscript received 18 January 2002.

Accepted 14 February 2002. 